\title{
Household factors associated with access to insecticide-treated nets and house modification in Bagamoyo and Ulanga districts, Tanzania
}

Olukayode G. Odufuwa ${ }^{1 *}$ D, Amanda Ross ${ }^{2,3}$, Yeromin P. Mlacha1,2,3, Omary Juma', Selemani Mmbaga', Daniel Msellemu ${ }^{1,2,3}$ and Sarah Moore ${ }^{1,2,3}$

\begin{abstract}
Background: Insecticide-treated nets (ITNs) and house modifications are proven vector control tools, yet in most regions, full coverage has not been achieved. This study investigates household factors associated with access to ITNs and house modification in Tanzania.

Methods: Baseline cross-sectional survey data from previous studies on spatial repellants and indoor residual spray evaluation was analysed from 6757 households in Bagamoyo (60 km north of Dar es Salaam) and 1241 households in Ulanga (a remote rural area in southeast Tanzania), respectively. Regression models were used to estimate the associations between the outcomes: population access to ITNs, access to ITN per sleeping spaces, window screens and closed eaves, and the covariates household size, age, gender, pregnancy, education, house size, house modification (window screens and closed eaves) and wealth.
\end{abstract}

Results: Population access to ITNs (households with one ITN per two people that stayed in the house the previous night of the survey) was 69\% ( $n=4663)$ and access to ITNs per sleeping spaces (households with enough ITNs to cover all sleeping spaces used the previous night of the survey) was $45 \%(n=3010)$ in Bagamoyo, 3 years after the last mass campaign. These findings are both lower than the least $80 \%$ coverage target of the Tanzania National Malaria Strategic Plan (Tanzania NMSP). In Ulanga, population access to ITNs was $92 \%(n=1143)$ and ITNs per sleeping spaces was $88 \%(n=1093), 1$ year after the last Universal Coverage Campaign (UCC). Increased household size was significantly associated with lower access to ITNs even shortly after UCC. House modification was common in both areas but influenced by wealth. In Bagamoyo, screened windows were more common than closed eaves (65\% vs 13\%), whereas in Ulanga more houses had closed eaves than window screens (55\% vs 12\%).

Conclusion: Population access to ITNs was substantially lower than the targets of the Tanzania NMSP after 3 years and lower among larger households after 1 year following ITN campaign. House modification was common in both areas, associated with wealth. Improved access to ITNs and window screens through subsidies and Behaviour Change Communication (BCC) strategies, especially among large and poor households and those headed by people with a low level of education, could maximize the uptake of a combination of these two interventions.

*Correspondence: oodufuwa@ihi.or.tz; olukayode.odufuwa2014@gmail.com

1 Ifakara Health Institute, Bagamoyo, Tanzania

Full list of author information is available at the end of the article

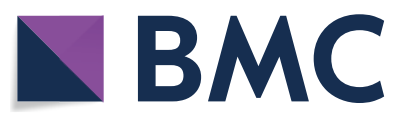

(c) The Author(s) 2020. This article is licensed under a Creative Commons Attribution 4.0 International License, which permits use, sharing, adaptation, distribution and reproduction in any medium or format, as long as you give appropriate credit to the original author(s) and the source, provide a link to the Creative Commons licence, and indicate if changes were made. The images or other third party material in this article are included in the article's Creative Commons licence, unless indicated otherwise in a credit line to the material. If material is not included in the article's Creative Commons licence and your intended use is not permitted by statutory regulation or exceeds the permitted use, you will need to obtain permission directly from the copyright holder. To view a copy of this licence, visit http://creativeco mmons.org/licenses/by/4.0/. The Creative Commons Public Domain Dedication waiver (http://creativecommons.org/publicdomain/ zero/1.0/) applies to the data made available in this article, unless otherwise stated in a credit line to the data. 
Keywords: Access, Insecticide Treated nets, ITNs, House modification, Malaria, Demographic, Socioeconomic, Vectorborne diseases, Tanzania

\section{Background}

Insecticide-treated nets (ITNs) have made the greatest contribution to the reduction in malaria burden in subSaharan Africa [1], through both individual and community effects [2]. The community effect works better when there is a high coverage of ITNs [2]. Hence, ITNs are recommended by the World Health Organization (WHO) to be universally and continuously distributed to all people at risk in malaria endemic regions [3]. Multiple ITN delivery strategies and campaigns have been implemented across sub-Saharan Africa, either targeting specific malaria risk populations (children under 5 years of age and pregnant women), or targeting the entire population through health facilities, antenatal clinics (ANC), schools, markets, door-to-door and other methods [4-7]. Despite more than a decade of ITN campaigns, an average of about $60 \%$ of the population in malaria endemic areas, still do not have access to an ITN [8], indicating that greater malaria control could be attained with improved access to this highly effective intervention.

House modification provides additional protection from all mosquitoes when people are indoors but not under their ITN [9], The installation of window screens or blocking of eaves (Fig. 1) acts to create barrier against mosquito entry and have been shown to be associated with lower malaria infection [10] and are a control tool for other vector-borne diseases such as dengue [11], arbovirus and lymphatic filariasis [12]. They (1) require no active compliance, (2) tend to be long-lasting and (3) protect all members of a household, 4) improving house ventilation and (5) preventing mosquito entry and nuisance $[13,14]$. House modification is not currently delivered operationally as a vector control tool. It is facing limited support from government or other organizations [15], being generally considered too costly to install or difficult to implement [14] as a public health intervention. However, there is evidence of an increasing number of houses with window screens and closed eaves among the urban Tanzanian population especially window screens [13].

This paper reports the household factors associated with access to ITNs and house modification between two rural populations: one far from and one close to an urban centre, as it is known that access to economic centers affects the economic, education, and health status of populations [16]. This work will provide information to policy-makers on identifying the gaps among different household settings and maximizing access to and use of these existing malaria control tools.

\section{Methods}

\section{Study area and socio-demographic characteristics}

The study was conducted in Bagamoyo and Ulanga districts (Fig. 2). Bagamoyo district is located on the east coast of Tanzania, approximately $60 \mathrm{~km}$ north of Dar es Salaam, the economic hub of the country [17] and Ulanga district is located in rural south-east Tanzania, $300 \mathrm{~km}$ from the regional city of Morogoro and $500 \mathrm{~km}$ from Dar es Salaam [18]. In Bagamoyo and Ulanga, the average household size was 4.4 and 4.9 persons per household, respectively according to the 2012 Tanzania National Census [19]. Adult literacy in Bagamoyo was $58 \%$ and $66 \%$ in Ulanga [20]. The average rainfall and temperature are 1200 to $2100 \mathrm{~mm}$ per year and approximately $28{ }^{\circ} \mathrm{C}$ in both districts, with slightly higher average rainfall per year and temperature in Bagamoyo due to its coastal location. Above $70 \%$ of the residents in both districts own pieces of land and the majority of them engage in subsistence farming $[18,21]$. The pattern of climatic conditions and land use are contributing factors toward malaria transmission [22].

\section{Study design}

The study is a secondary analysis of two baseline crosssectional surveys from a trial on spatial repellents in Bagamoyo [23], and an insecticide residual spray (IRS) evaluation in Ulanga [24]. The surveys were continuously conducted randomly in nine villages in the Bagamoyo district from November 2014 to October 2015 and eight villages in Ulanga district from December 2016 to June 2017, covering both dry and rainy season.

\section{Household survey data collection}

Data were collected using a structured questionnaire upon written informed consent from an adult household member. The questionnaire surveyors collected information on ITN coverage indicators: (1) households with at least one ITN for every two people that slept in the household [25] and (2) households with one ITN per sleeping space [26], to investigate the coverage achieved by the Universal Coverage Campaign (UCC) conducted from the mid-year 2015 to 2017, to cover all sleeping spaces that were recorded to be unreached [4].

Information was collected on demographic and socioeconomic characteristics, household geographical 

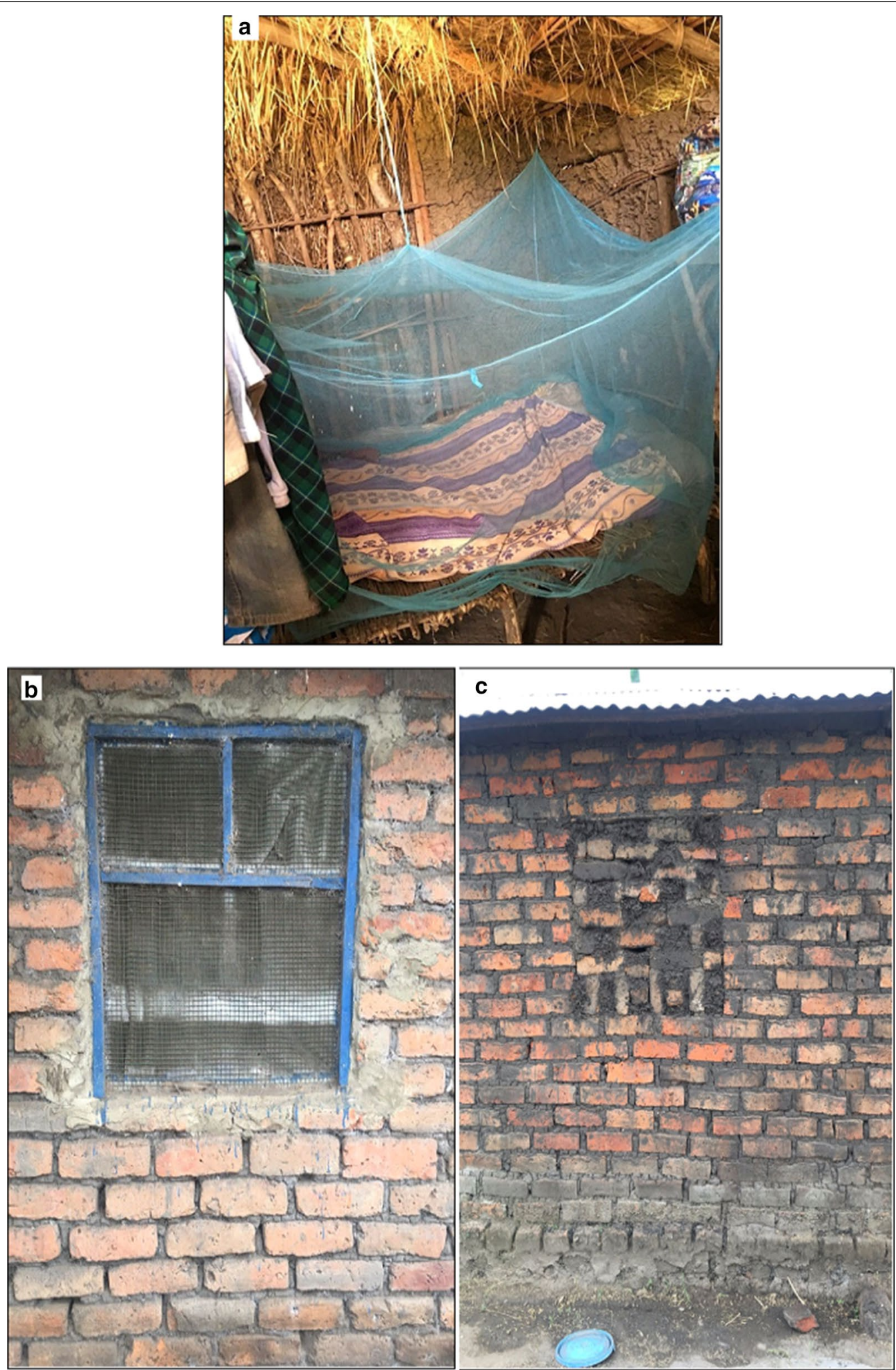

Fig. 1 a An ITN hanging in a rural Tanzanian home. b Screened window. c Eaves and ventilation bricks closed with mud to prevent mosquito entry 


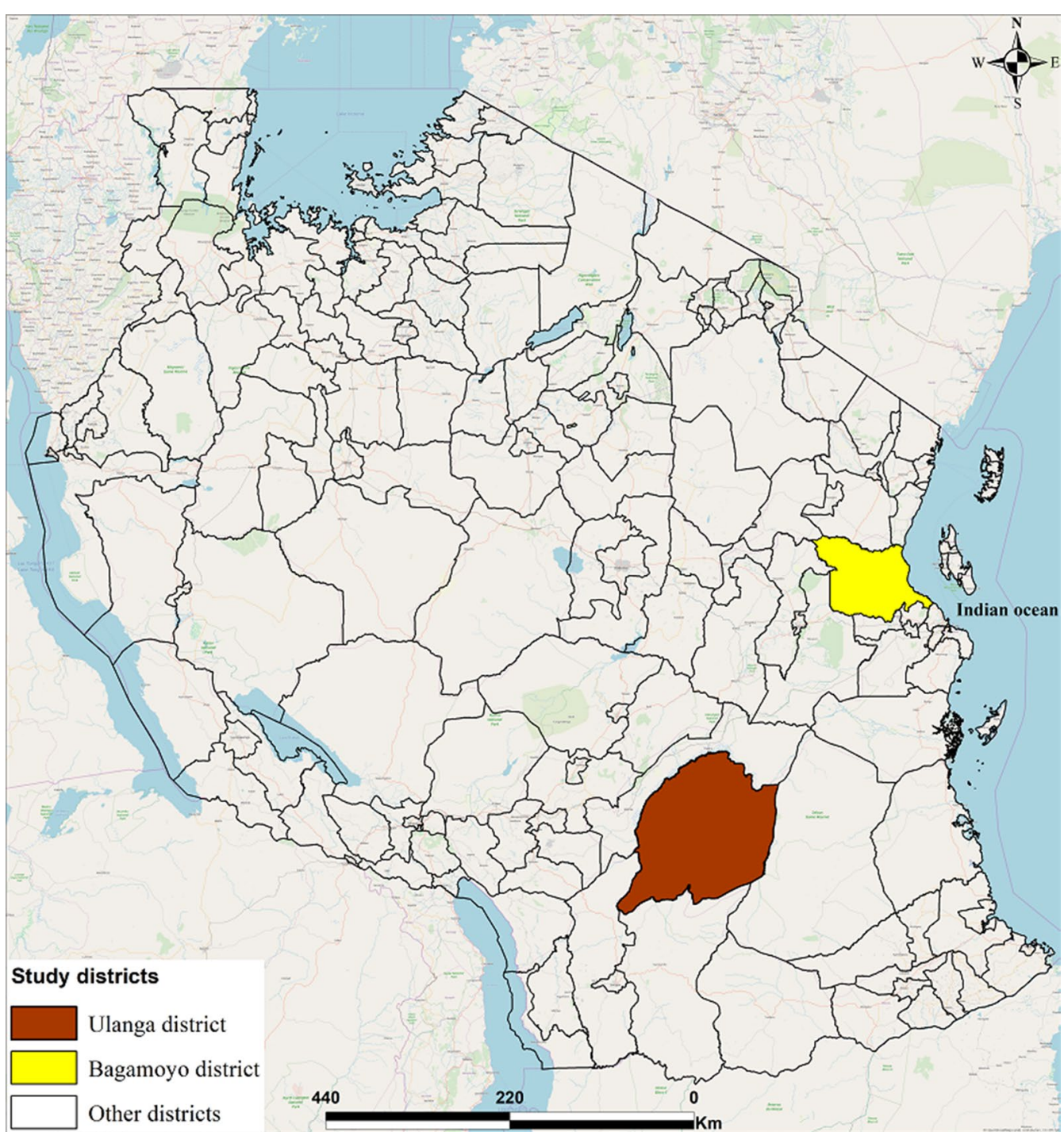

Fig. 2 Geographical location of Bagamoyo and Ulanga districts in Tanzania. Openstreet base map obtained from the ArcGIS plugin

coordinates (longitude, latitude and elevation) and notes on the house structure were made based on observation by the interviewers. Information on age, gender and level of formal education was collected for the head of households, and the total number of pregnant women within each household was also recorded. The surveys were delivered using similar questionnaires in the two sites except that in Ulanga, data on age, gender and educational status of heads of households and the geographical coordinates were not collected.

\section{Data management and analysis}

The paper questionnaires were double-entered using EpiData software [27] and analysis was carried out using
STATA 14.2 [28]. The socioeconomic status of each household was derived from a weighted score using principal component analysis (PCA), categorized into quintiles: lowest, low, middle, high and highest [29]. PCA analysis was conducted separately in Bagamoyo and Ulanga. In Bagamoyo, the variables selected for the PCA analysis were ownership of durable asset (radio, mobile phone, fan, television, iron, refrigerator and cable television), farm animals (chickens, ducks, goats, cows, dogs), a means of transportation (animal cart, bicycle, motorcycle, canoe, tricycle, ark, and car), access to utilities (water and toilet) and a light source (candle, electricity, battery/ solar panel, hurricane lamp, kerosene and fire), and house structure (wall, roof, ceiling and floor). Similar variables 
were selected for the PCA analysis in Ulanga except that torch-light was added as a form of light source, and, other variables such as fan, iron, refrigerator, animal cart, canoe, tricycle, ark and car were excluded, as none of the households in Ulanga possessed them.

The population access to ITNs was defined as the whether or not there was at least one net available on the previous night per two people who slept in the household on the previous night. Access to ITN per sleeping space was defined as available net the previous night in each sleeping space which had been used the previous night. Indicators of population access to ITNs and access to ITNs for sleeping spaces were defined in line with the household survey indicators for malaria control [30].

The outcomes, population access to ITNs, access to ITN per sleeping spaces, presence of window screens and the presence of closed eaves were analysed using a logistic regression model. The associations between the outcomes and the covariates of household size, age, gender, pregnancy, education, house size, house modification (window screens and closed eaves), and socioeconomic quintiles were estimated. The village was included in the regression model as a random effect to account for clustering. The ages of the heads of households were categorized into three levels: young adults "18-24", adult "25-49" and old adults "50-99". Household size was also categorized into two levels, small and average household size " $1-5$ " and large household size " 6 and above". The number of doors and windows were added together and categorized into two levels: small and average house size "1-4" and large house size " 5 and above" to indicate the physical size of houses.

All covariates and interaction between education and wealth status were considered in the analysis based on findings from past literature [31-35]. The likelihoodratio test was conducted by comparing the model with all covariates against the model without each covariate one after the other and the p-values were reported. Collinearity was investigated using the Collin program in STATA and no unacceptable correlation was suspected [36].

\section{Results}

\section{Demographic and socioeconomic characteristics of households}

A total of 6757 households in Bagamoyo and 1241 in Ulanga districts were surveyed (Table 1). The mean household size in Bagamoyo and Ulanga districts was 4.38 and 3.78, respectively. The mean number of sleeping spaces in Bagamoyo was 2.67 and 1.85 in Ulanga. From data collected in Bagamoyo only, fewer households ( $9 \%$ [ $\mathrm{n}=594]$ ) were headed by young adults (18 to 24 years). Roughly, $77 \%$ [ $n=5174]$ of the households in Bagamoyo were headed by a male and most of the head of households had primary education (71\% [ $\mathrm{n}=4829])$. The proportion of large houses was greater in Bagamoyo $(44 \%[n=2999])$ than Ulanga $(26 \%[n=327])$, indicating more wealthy households in Bagamoyo than Ulanga district (Table 1).

\section{Access to ITNs in the population}

In Bagamoyo, 3 years after a mass distribution campaign, population access to ITNs (proportion of households with one ITN for two potential users that stayed in the house the previous night of the survey) was estimated as $69 \%$ [ $n=4663$ ]. Access to one ITN per sleeping space (total number of households with enough ITNs to cover all sleeping spaces used the previous night of the survey) was estimated as $45 \%[n=3010]$. These estimates are lower than the least $80 \%$ coverage targets of the Tanzania National Malaria Operational Plan 2019 [37]. In Ulanga, 1 year after a mass distribution campaign, population access to ITN was $92 \%[n=1143]$ and ITN per sleeping spaces was $88 \%$ [ $n=1093]$.

\section{Household factors associated with access to ITNs in Bagamoyo and Ulanga}

The household factors associated with having greater access to ITNs for two potential sleepers in Bagamoyo in the multivariable analysis were having screened windows or closed eaves, a smaller household size, older head of household, a higher level of education, and a larger physical house size. In Ulanga, a smaller household size and a larger physical house size were both also significantly associated with having access to ITN for two potential sleepers. Wealth quintile was also associated, but whereas in Bagamoyo the higher quintile had the highest access, in Ulanga it was the lowest wealth quintile (Table 2).

Similar variables were associated with access to ITNs per sleeping space (Table 3) in Bagamoyo and Ulanga, except that in Ulanga there was only evidence for greater access to ITN by sleeping space in houses that were smaller in physical size.

\section{House modifications (Houses having window screens and closed eaves) in the population}

In Bagamoyo, 65\% [ $\mathrm{n}=4392]$ of houses had window screens, compared to $12 \%[n=150]$ in Ulanga. Closed eaves were observed in 13\% [ $n=904]$ of houses in Bagamoyo and 55\% [ $\mathrm{n}=679]$ of houses in Ulanga. About half $(47 \%[n=3157])$ of the houses with screened windows in Bagamoyo also had sufficient access to ITNs and in Ulanga, $51 \%$ [ $n=638$ ] of houses with closed eaves had sufficient access to ITNs (Table 1). 


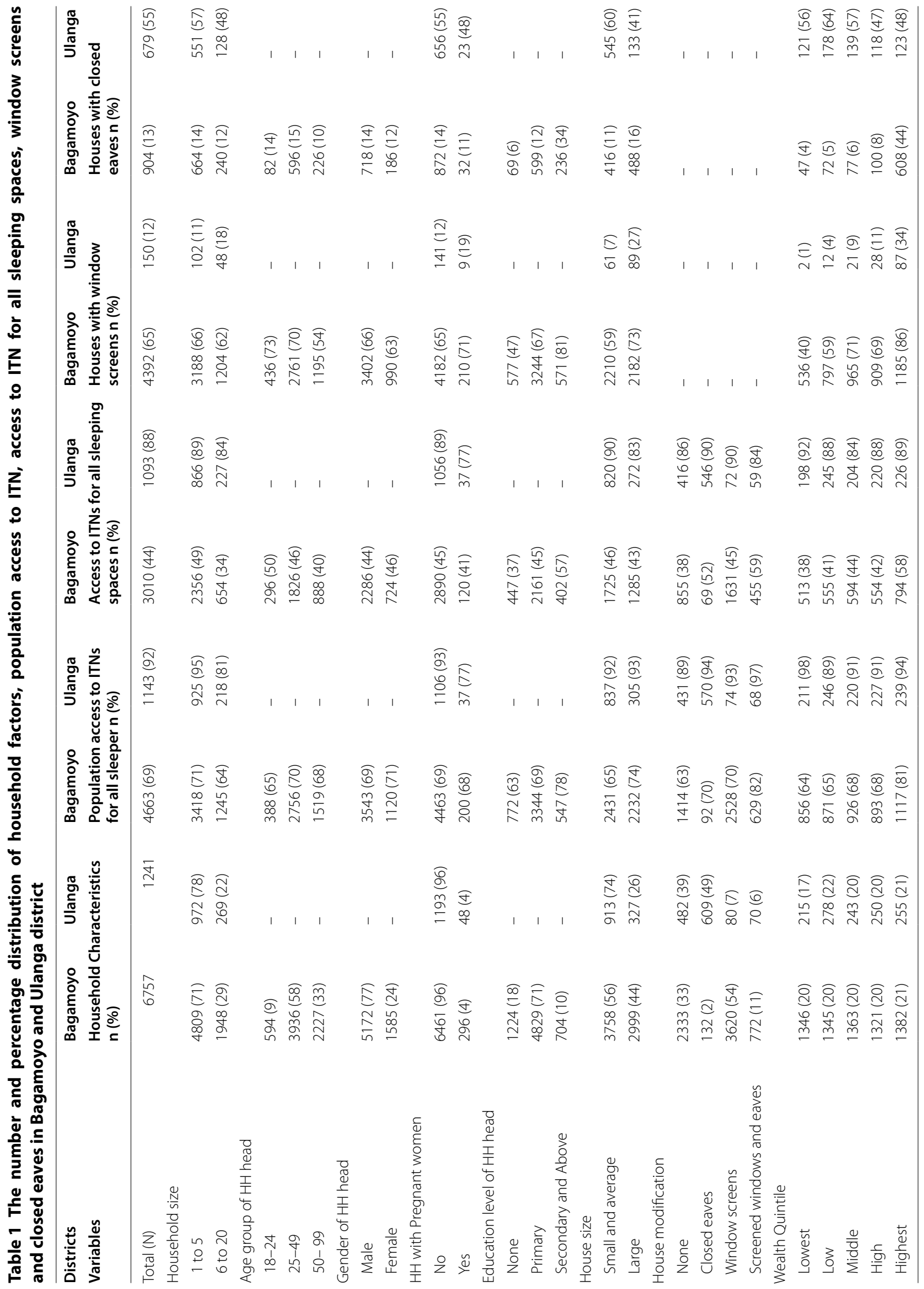


Table 2 Association between household factors and having access to ITNs for two potential sleepers in the population

\begin{tabular}{|c|c|c|c|c|c|c|c|c|c|c|}
\hline \multirow{3}{*}{$\begin{array}{l}\text { Districts } \\
\text { Models } \\
\text { Co-variates }\end{array}$} & \multicolumn{5}{|c|}{ Bagamoyo } & \multicolumn{5}{|c|}{ Ulanga } \\
\hline & \multicolumn{2}{|c|}{ Univariate } & \multicolumn{3}{|c|}{ Multivariable } & \multicolumn{2}{|c|}{ Univariate } & \multicolumn{3}{|c|}{ Multivariable } \\
\hline & OR & $95 \% \mathrm{Cl}$ & OR & $95 \% \mathrm{Cl}$ & P-value & OR & $95 \% \mathrm{Cl}$ & OR & $95 \% \mathrm{Cl}$ & P-value \\
\hline \multicolumn{11}{|l|}{ Household size } \\
\hline $1-5$ & 1 & & 1 & & 0.001 & 1 & & 1 & & 0.001 \\
\hline 6 and above & 0.72 & $0.64-0.81$ & 0.63 & $0.55-0.71$ & & 0.22 & $0.14-0.33$ & 0.31 & $0.18-0.52$ & \\
\hline \multicolumn{11}{|l|}{ Age group of $\mathrm{HH}$ head } \\
\hline $18-24$ & 1 & & 1 & & 0.041 & - & - & - & - & - \\
\hline $25-49$ & 1.24 & $1.03-1.49$ & 1.26 & $1.04-1.53$ & & - & - & - & - & - \\
\hline 50 and above & 1.14 & $0.94-1.38$ & 1.16 & $0.94-1.43$ & & - & - & - & - & - \\
\hline \multicolumn{11}{|l|}{ Gender of $\mathrm{HH}$ head } \\
\hline Male & 1 & & 1 & & 0.101 & - & - & - & - & - \\
\hline Female & 1.11 & $0.98-1.25$ & 1.12 & $0.98-1.28$ & & - & - & - & - & - \\
\hline \multicolumn{11}{|c|}{ Households with pregnant women } \\
\hline No & 1 & & 1 & & 0.910 & 1 & & 1 & & 0.170 \\
\hline Yes & 0.93 & $0.73-1.20$ & 1.02 & $0.78-1.32$ & & 0.26 & $0.13-0.54$ & 0.51 & $0.19-1.32$ & \\
\hline \multicolumn{11}{|c|}{ Level of formal Education of $\mathrm{HH}$ head } \\
\hline None & 1 & & 1 & & 0.001 & - & - & - & - & - \\
\hline Primary & 1.32 & $1.16-1.50$ & 1.31 & $1.13-1.52$ & & - & - & - & - & - \\
\hline Secondary and above & 2.04 & $1.65-2.52$ & 1.55 & $1.22-1.96$ & & - & - & - & - & - \\
\hline \multicolumn{11}{|l|}{ House size } \\
\hline Small and average & 1 & & 1 & & 0.001 & 1 & & 1 & & 0.010 \\
\hline Large & 1.59 & $1.71-1.96$ & 1.58 & $1.39-1.78$ & & 1.26 & $0.77-2.06$ & 2.34 & $1.20-4.58$ & \\
\hline \multicolumn{11}{|l|}{ House entry protected } \\
\hline None & 1 & & 1 & & 0.001 & 1 & & 1 & & 0.063 \\
\hline Closed eaves & 1.33 & $0.91-1.95$ & 0.95 & $0.64-1.43$ & & 1.73 & $1.12-2.67$ & 1.72 & $1.00-2.93$ & \\
\hline Screened windows & 1.34 & $1.20-1.50$ & 1.27 & $1.12-1.44$ & & 1.46 & $0.60-3.52$ & 1.75 & $0.62-4.95$ & \\
\hline $\begin{array}{l}\text { Screened windows and } \\
\text { closed eaves }\end{array}$ & 2.55 & $2.08-3.11$ & 1.53 & $1.21-1.94$ & & 4.02 & $0.96-16.91$ & 4.41 & $0.93-20.90$ & \\
\hline \multicolumn{11}{|l|}{ Wealth Quintile } \\
\hline Lowest & 1 & & 1 & & 0.001 & 1 & & 1 & & 0.041 \\
\hline Low & 1.05 & $0.90-1.23$ & 0.86 & $0.73-1.02$ & & 0.15 & $0.05-0.42$ & 0.22 & $0.07-0.67$ & \\
\hline Middle & 1.21 & $1.03-1.42$ & 1.01 & $0.85-1.20$ & & 0.18 & $0.06-0.53$ & 0.27 & $0.09-0.86$ & \\
\hline High & 1.19 & $1.02-1.40$ & 0.87 & $0.73-1.03$ & & 0.19 & $0.06-0.55$ & 0.24 & $0.08-0.77$ & \\
\hline Highest & 2.41 & $2.03-2.87$ & 1.41 & $1.15-1.73$ & & 0.28 & $0.09-0.86$ & 0.22 & $0.06-0.76$ & \\
\hline
\end{tabular}

The first level in each variable with the value 1 represents the reference group

Household factors associated with houses having window screens and closed eaves in the population

Window screens were more likely to be installed in houses with smaller household size, younger head of household, higher level of education, higher wealth quintile, large houses and sufficient access to ITNs (Table 4). In Ulanga, large house size and higher wealth quintile were associated with window screening (Table 4). Similar to what was observed with window screens, houses that had closed eaves were common among those that head of households were younger people, had high level of education and in the higher wealth quintile in Bagamoyo
(Table 5). While in Ulanga, closed eaves were more likely in houses with smaller physical size and sufficient access to ITNs (Table 5).

\section{Discussion}

\section{ITNs coverage in the population}

Population access to ITNs and access to ITNs for all sleeping spaces, 3 years following a mass distribution campaign in Bagamoyo was lower than the least $80 \%$ coverage targets of the Tanzania National Malaria Strategic Plan. This is consistent with findings that the functional survival time of long-lasting insecticidal nets is less than 
Table 3 Association between household factors and having access to ITNs for all sleeping spaces

\begin{tabular}{|c|c|c|c|c|c|c|c|c|c|c|}
\hline \multirow{3}{*}{$\begin{array}{l}\text { Districts } \\
\text { Models } \\
\text { Covariates }\end{array}$} & \multicolumn{5}{|c|}{ Bagamoyo } & \multicolumn{5}{|c|}{ Ulanga } \\
\hline & \multicolumn{2}{|c|}{ Univariate } & \multicolumn{3}{|c|}{ Multivariable } & \multicolumn{2}{|c|}{ Univariate } & \multicolumn{3}{|c|}{ Multivariable } \\
\hline & OR & $95 \% \mathrm{Cl}$ & OR & $95 \% \mathrm{Cl}$ & P-value & OR & $95 \% \mathrm{Cl}$ & OR & $95 \% \mathrm{Cl}$ & P-value \\
\hline \multicolumn{11}{|l|}{ Household size } \\
\hline 1 to 5 & 1 & & 1 & & 0.001 & 1 & & 1 & & 0.78 \\
\hline 6 to 20 & 0.53 & $0.47-0.59$ & 0.58 & $0.51-0.66$ & & 0.66 & $0.45-0.97$ & 1.07 & $0.68-1.66$ & \\
\hline \multicolumn{11}{|l|}{ Age group of $\mathrm{HH}$ head } \\
\hline $18-24$ & 1 & & 1 & & 0.006 & - & - & - & - & - \\
\hline $25-49$ & 0.87 & $0.73-1.04$ & 1.01 & $0.84-1.22$ & & - & - & - & - & - \\
\hline 50-99 & 0.67 & $0.56-0.80$ & 0.83 & $0.68-1.02$ & & - & - & - & - & - \\
\hline \multicolumn{11}{|l|}{ Gender of $\mathrm{HH}$ head } \\
\hline Male & 1 & & 1 & & 0.234 & - & - & - & - & - \\
\hline Female & 1.06 & $0.95-1.19$ & 1.08 & $0.95-1.22$ & & - & - & - & - & - \\
\hline \multicolumn{11}{|c|}{ Households with pregnant women } \\
\hline No & 1 & & 1 & & 0.357 & 1 & & 1 & & 0.15 \\
\hline Yes & 0.84 & $0.66-1.07$ & 0.89 & $0.69-1.14$ & & 0.44 & $0.22-0.86$ & 0.56 & $0.26-1.20$ & \\
\hline \multicolumn{11}{|c|}{ Level of formal education of $\mathrm{HH}$ head } \\
\hline None & 1 & & 1 & & 0.001 & - & - & - & - & - \\
\hline Primary & 1.41 & $1.24-1.60$ & 1.41 & $1.22-1.63$ & & - & - & - & - & - \\
\hline Secondary and above & 2.31 & $1.91-2.80$ & 1.75 & $1.41-2.18$ & & - & - & - & - & - \\
\hline \multicolumn{11}{|l|}{ House size } \\
\hline Small and average & 1 & & 1 & & 0.002 & 1 & & 1 & & 0.002 \\
\hline Large & 0.88 & $0.80-0.97$ & 0.83 & $0.74-0.93$ & & 0.56 & $0.39-0.80$ & 0.50 & $0.32-0.78$ & \\
\hline \multicolumn{11}{|l|}{ House entry protected } \\
\hline None & 1 & & 1 & & 0.001 & 1 & & 1 & & 0.583 \\
\hline Closed eaves & 1.77 & $1.24-2.51$ & 1.27 & $0.88-1.85$ & & 1.38 & $0.95-1.99$ & 1.17 & $0.79-1.73$ & \\
\hline Screened windows & 1.32 & $1.19-1.47$ & 1.35 & $1.20-1.53$ & & 1.43 & $0.66-3.10$ & 1.65 & $0.72-3.81$ & \\
\hline $\begin{array}{l}\text { Screened windows and } \\
\text { closed eaves }\end{array}$ & 2.31 & $1.96-2.73$ & 1.54 & $1.26-1.89$ & & 0.85 & $0.43-1.70$ & 0.96 & $0.45-2.05$ & \\
\hline \multicolumn{11}{|l|}{ Wealth Quintile } \\
\hline Lowest & 1 & & 1 & & 0.001 & 1 & & 1 & & 0.231 \\
\hline Low & 1.14 & $0.98-1.33$ & 0.94 & $0.80-1.11$ & & 0.64 & $0.34-1.18$ & 0.67 & $0.35-1.27$ & \\
\hline Middle & 1.25 & $1.08-1.46$ & 1.13 & $0.96-1.34$ & & 0.45 & $0.25-0.82$ & 0.54 & $0.28-1.02$ & \\
\hline High & 1.17 & $1.00-1.37$ & 0.94 & $0.79-1.11$ & & 0.63 & $0.34-1.18$ & 0.82 & $0.42-1.61$ & \\
\hline Highest & 2.19 & $1.88-2.56$ & 1.52 & $1.26-1.82$ & & 0.67 & $0.36-1.25$ & 0.9 & $0.43-1.89$ & \\
\hline
\end{tabular}

The first level in each variable with the value 1 represents the reference group

3 years in field use $[38,39]$. The average interval between campaigns in Tanzania is at least 4 years, thus many people may be unprotected from malaria vectors during the interval.

Family size is an important factor that needs to be considered when planning ITN distribution campaigns according to this study's finding of low coverage in large households compared to average and small households in both Bagamoyo and Ulanga districts. Larger households may have more children, who are more likely to share sleeping space with their parents or a sleeping space occupied by more than two children. This finding has also been observed in the lake region of Tanzania where household numbers are on average larger, (Ikupa Akim pers. comm). Therefore, our study demonstrates bed net campaigns should consider removing the current limit on the maximum number of nets allowed per household, in order to achieve high ITN coverage among households of large size.

The sleeping pattern, where more than 2 people share a net (crowding) among large households and those with children, has been found to decrease the durability of ITNs due to net stretching, resulting in more rapid loss of ITNs due to damage among this group compared to 
Table 4 Household factors associated with houses that had window screens in the population

\begin{tabular}{|c|c|c|c|c|c|c|c|c|c|c|}
\hline \multirow{3}{*}{$\begin{array}{l}\text { Districts } \\
\text { Models } \\
\text { Covariates }\end{array}$} & \multicolumn{5}{|c|}{ Bagamoyo } & \multicolumn{5}{|c|}{ Ulanga } \\
\hline & \multicolumn{2}{|c|}{ Univariate } & \multicolumn{3}{|c|}{ Multivariable } & \multicolumn{2}{|c|}{ Univariate } & \multicolumn{3}{|c|}{ Multivariable } \\
\hline & OR & $95 \% \mathrm{Cl}$ & OR & $95 \% \mathrm{Cl}$ & P-value & OR & $95 \% \mathrm{Cl}$ & OR & $95 \% \mathrm{Cl}$ & P-value \\
\hline \multicolumn{11}{|l|}{ Household size } \\
\hline 1 to 5 & 1 & & 1 & & 0.001 & 1 & & 1 & & 0.833 \\
\hline 6 to 20 & 0.82 & $0.74-0.92$ & 0.68 & $0.59-0.77$ & & 1.85 & $1.28-2.69$ & 1.05 & $0.67-1.66$ & \\
\hline \multicolumn{11}{|l|}{ Age group of $\mathrm{HH}$ head } \\
\hline $18-24$ & 1 & & 1 & & 0.001 & - & - & - & - & - \\
\hline $25-49$ & 0.85 & $0.70-1.03$ & 0.76 & $0.61-0.94$ & & - & - & - & - & - \\
\hline $50-99$ & 0.42 & $0.34-0.51$ & 0.42 & $0.33-0.53$ & & - & - & - & - & - \\
\hline \multicolumn{11}{|l|}{ Gender of $\mathrm{HH}$ head } \\
\hline Male & 1 & & 1 & & 0.409 & - & - & - & - & - \\
\hline Female & 0.87 & $0.77-0.97$ & 1.06 & $0.92-1.22$ & & - & - & - & - & - \\
\hline \multicolumn{11}{|c|}{ Households with pregnant women } \\
\hline No & 1 & & 1 & & 0.208 & 1 & & 1 & & 0.123 \\
\hline Yes & 1.33 & $1.03-1.72$ & 1.2 & $0.90-1.59$ & & 1.72 & $0.82-3.63$ & 2.05 & $0.85-4.93$ & \\
\hline \multicolumn{11}{|c|}{ Level of formal education of $\mathrm{HH}$ Head } \\
\hline None & 1 & & 1 & & 0.001 & - & - & - & - & - \\
\hline Primary & 2.29 & $2.02-2.61$ & 1.54 & $1.33-1.79$ & & - & - & - & - & - \\
\hline Secondary and above & 4.81 & $3.87-6.00$ & 2.1 & $1.64-2.70$ & & - & - & - & - & - \\
\hline \multicolumn{11}{|l|}{ House size } \\
\hline Small and average & 1 & & 1 & & 0.001 & 1 & & 1 & & 0.001 \\
\hline Large & 1.87 & $1.69-2.07$ & 2.06 & $1.82-2.34$ & & 5.22 & $3.66-7.46$ & 2.91 & $1.86-4.53$ & \\
\hline \multicolumn{11}{|l|}{ Wealth Quintile } \\
\hline Lowest & 1 & & 1 & & 0.001 & 1 & & 1 & & 0.001 \\
\hline Low & 2.2 & $1.88-2.56$ & 2.28 & $1.93-2.68$ & & 4.8 & $1.06-21.70$ & 4.61 & $1.01-21.06$ & \\
\hline Middle & 3.66 & $3.12-4.30$ & 3.33 & $2.81-3.94$ & & 10.07 & $2.33-43.49$ & 8.92 & $2.03-39.19$ & \\
\hline High & 3.33 & $2.84-3.91$ & 3.18 & $2.68-3.78$ & & 13.43 & $3.16-57.08$ & 11.3 & $2.60-49.15$ & \\
\hline Highest & 9.09 & $7.55-10.95$ & 7.88 & $6.44-9.65$ & & 55.15 & $13.38-227.32$ & 41.54 & $9.67-178.54$ & \\
\hline \multicolumn{11}{|l|}{ Access to ITNs } \\
\hline No & 1 & & 1 & & 0.001 & 1 & & 1 & & 0.06 \\
\hline Yes & 1.46 & $1.31-1.62$ & 1.3 & $1.15-1.47$ & & 1.6 & $0.76-3.36$ & 2.23 & $0.92-5.40$ & \\
\hline
\end{tabular}

The first level in each variable with the value 1 represents the reference group

those with smaller or average household [40], [41], Additional efforts are required to improve population access to ITNs that consider the demography and sleeping pattern of individual households.

Mosquitoes are more attracted to households with an increased number of people [42], thus households with larger family sizes need to have adequate ITNs to impact malaria. ITNs distribution in schools as a keep-up strategy may provide additional coverage for larger households [43]. School-age children tend to have the lowest access to ITNs [44], therefore the school nets program in Tanzania is a useful strategy to help target this vulnerable group.

In Bagamoyo, there was also inequity to access to ITNs among several demographic factors: (1) age groups, especially among households headed by younger adults (18 to 24 years old), perhaps the households with younger heads fall in the reproductive age group and would normally have new children after mass distribution of ITNs; (2) educational attainment of head of households, information on the importance of ITN use for malaria prevention may be lagging among those with less formal education, which has been seen widely, for instance in Ghana [45]; and (3) Wealth status, rich people purchased ITNs when the ones they were given by the campaign became non-functional. On the other hand, in Ulanga, where ITNs were recently distributed, the wealthiest households had lower access to ITNs. This may be attributed to working household members not being present at home during the distribution process, as was observed 
Table 5 Household factors associated with houses that had closed eaves in the population

\begin{tabular}{|c|c|c|c|c|c|c|c|c|c|c|}
\hline \multirow{3}{*}{$\begin{array}{l}\text { Districts } \\
\text { Models } \\
\text { Covariates }\end{array}$} & \multicolumn{5}{|c|}{ Bagamoyo } & \multicolumn{5}{|l|}{ Ulanga } \\
\hline & \multicolumn{2}{|c|}{ Univariate } & \multicolumn{2}{|c|}{ Multivariable } & \multirow[b]{2}{*}{ P-value } & \multirow{2}{*}{$\begin{array}{l}\text { Univariate } \\
\text { OR }\end{array}$} & \multirow[b]{2}{*}{$95 \% \mathrm{Cl}$} & \multirow{2}{*}{$\begin{array}{l}\text { Multivariable } \\
\text { OR }\end{array}$} & \multirow[b]{2}{*}{$95 \% \mathrm{Cl}$} & \multirow[t]{2}{*}{ P-value } \\
\hline & OR & $95 \% \mathrm{Cl}$ & OR & $95 \% \mathrm{Cl}$ & & & & & & \\
\hline \multicolumn{11}{|l|}{ Household size } \\
\hline 1 to 5 & 1 & & 1 & & 0.074 & 1 & & 1 & & 0.711 \\
\hline 6 to 20 & 0.88 & $0.75-1.03$ & 0.84 & $0.69-1.02$ & & 1.31 & $1.15-1.49$ & 0.94 & $0.70-1.28$ & \\
\hline \multicolumn{11}{|l|}{ Age group of $\mathrm{HH}$ head } \\
\hline $18-24$ & 1 & & 1 & & $0.010 z$ & - & - & - & - & - \\
\hline $25-49$ & 1.11 & $0.87-1.43$ & 1.08 & $0.81-1.46$ & & - & - & - & - & - \\
\hline $50-99$ & 0.71 & $0.54-0.92$ & 0.81 & $0.58-1.12$ & & - & - & - & - & - \\
\hline \multicolumn{11}{|l|}{ Gender of HH head } \\
\hline Male & 1 & & 1 & & 0.817 & - & - & - & - & - \\
\hline Female & 0.82 & $0.69-0.98$ & 0.98 & $0.80-1.20$ & & - & - & - & - & - \\
\hline \multicolumn{11}{|c|}{ Households with pregnant women } \\
\hline No & 1 & & 1 & & 0.126 & 1 & & 1 & & 0.928 \\
\hline Yes & 0.78 & $0.53-1.13$ & 0.72 & $0.48-1.11$ & & 0.75 & $0.42-1.34$ & 0.97 & $0.53-1.80$ & \\
\hline \multicolumn{11}{|c|}{ Level of formal Education of $\mathrm{HH}$ Head } \\
\hline None & 1 & & 1 & & 0.001 & - & - & - & - & - \\
\hline Primary & 2.37 & $1.83-3.07$ & 1.55 & $1.16-2.08$ & & - & - & - & - & - \\
\hline Secondary and above & 8.44 & $6.32-11.27$ & 2.89 & $2.06-4.05$ & & - & - & - & - & - \\
\hline \multicolumn{11}{|l|}{ House size } \\
\hline Small and average & 1 & & 1 & & 0.406 & 1 & & 1 & & 0.001 \\
\hline Large & 1.56 & $1.36-1.80$ & 1.08 & $0.90-1.30$ & & 0.46 & $0.36-0.60$ & 0.54 & $0.39-0.73$ & \\
\hline \multicolumn{11}{|l|}{ Wealth Quintile } \\
\hline Lowest & 1 & & 1 & & 0.001 & 1 & & 1 & & 0.057 \\
\hline Low & 1.56 & $1.07-2.28$ & 1.46 & $1.00-2.13$ & & 1.38 & $0.96-1.99$ & 1.62 & $1.10-2.37$ & \\
\hline Middle & 1.65 & $1.14-2.40$ & 1.52 & $1.05-2.21$ & & 1.04 & $0.72-1.50$ & 1.39 & $0.93-2.06$ & \\
\hline High & 2.26 & $1.59-3.23$ & 1.94 & $1.35-2.78$ & & 0.69 & $0.48-1.00$ & 1.03 & $0.69-1.53$ & \\
\hline Highest & 21.71 & $15.93-29.59$ & 15.55 & $11.29-21.44$ & & 0.72 & $0.50-1.04$ & 1.30 & $0.84-2.00$ & \\
\hline \multicolumn{11}{|l|}{ Access to ITNs } \\
\hline No & 1 & & 1 & & 0.084 & 1 & & 1 & & 0.025 \\
\hline Yes & 1.91 & $1.61-2.27$ & 1.19 & $0.98-1.45$ & & 1.76 & $1.16-2.67$ & 1.72 & $1.07-2.77$ & \\
\hline
\end{tabular}

The first level in each variable with the value 1 represents the reference group

during the collection of adverse events data at the end of the survey. In a nutshell, it is evident that there was inequity to access to ITNs in the population, as a result, the BCC strategy at the community level may be targeted towards all households to encourage continuous uptake, care of ITNs to improve ITN longevity and to encourage the continued use of damaged ITNs between campaigns, as it has been shown that damaged nets remain insecticidal [46]. It is clear, however, that more effort is needed in improving access to ITNs.

\section{House modification in the population}

A possible explanation for the higher proportion of houses with window screens in Bagamoyo, could be attributed to wealthier households and availability of low-cost screening, being closer to Dar es Salaam, the economic capital of Tanzania [13], as compared to Ulanga, a remote rural area with low income. The majority of the houses in Bagamoyo had opened eaves possibly due to low awareness of closed eaves as a tool to reduce indoor mosquito density [12], and high temperature during the daytime, as found in neighbouring coastal Kenya (Mombasa) [47]. This contrasts with findings in Ulanga where more of the houses blocked their eaves with mud. Having open eaves in houses is an efficient means of indoor cooling [12], which is also a plausible explanation for the observed pattern, especially since Bagamoyo has an average temperature $2{ }^{\circ} \mathrm{C}$ higher and greater humidity than Ulanga due to its proximity to the ocean. 
The strongest household factor associated with having window screens in both Bagamoyo and Ulanga was wealth. Wealthy households in Bagamoyo were more likely to have closed eaves where window screens were also in common use, while in Ulanga, the poorest households were more likely to close their eaves with mud to prevent mosquito indoor entry [48]. As wealth is strongly associated with window screening, it would be prudent for window screens to receive a subsidy and made more widely available as a long-term vector control intervention to protect all household members while indoorthrough indoor mosquito entry barriers. The acceptance of closed eaves in the rural areas do not seem worrisome as it is already a common housing structure among modern houses owned by wealthy people in Tanzania [49]. However, in houses with indoor fires, closing eaves is not advisable as it may increase exposure to biomass particulate matter and induce respiratory illness [50].

In contrast to having access to ITNs for two potential sleepers in Bagamoyo, window screens and closed eaves were more common in households headed by young individuals. This group had more years of formal education and were wealthier than the older age group, as access to education in Tanzania has steadily improved over the last decades [51]. This might have made them more knowledgeable about the importance of the tool in preventing indoor mosquito entry and their wealth afforded them the opportunity to install them in their houses. This also serves as an indicator that younger people are adaptive to the uptake of new tools for controlling malaria. However, installing window screens alone is not sufficient to control malaria [52], because mosquitoes may find their way indoor when doors are left open. The incorporation of insecticides into window screens would improve the efficacy of this tool against mosquitoes as it has improved the protective efficacy of conventional bed nets and other vector control tools [53], providing both individual and community protection-through killing vectors that come into contact with the screens. It is logical that maximizing the concurrent use of multiple vector control tools, i.e. combination of ITNs and insecticidal house screening will assist malaria elimination in Tanzania [54] and also protect against other vector-borne diseases [11], [12]. The combination of ITNs and house screening already occurs, where households with access to one ITN for every two members were more likely to have window screens in Bagamoyo and closed eaves in Ulanga, suggesting that they already understood that using bednets as a stand-alone malaria control tool is not sufficient.

It is important to stress the consideration of household size in vector control delivery system plans. In Bagamoyo, houses with large households were less likely to have access to ITNs and less likely to have window screens, despite the higher possibility of having more children residing in them. The possible reason for this was found, most of the large households were headed by people with low formal education, which reinforces the necessity of $\mathrm{BCC}$ strategy incorporation during distribution campaigns.

The study was affected by non-response and desirability bias [55], which might have influenced ITNs access estimates. It was suspected that respondents denied owning at least one ITN in the household due to an expectation of compensation in the form of ITNs after the study. Therefore, it was necessary to use the number of ITNs reported to be used the previous night as a proxy for ownership. This was more reliably measured as interviewers asked the use of each ITN with respect to where it was used in the household. Ideally, surveyors of ITN access should visually inspect the presence of nets in households whenever possible to reduce the possibility of respondents giving misleading answers. The study was unable to establish a standardized comparison between the study areas, as age, sex and educational status of heads of households in the Ulanga district were not collected. Nevertheless, the study recruited a very large number of participants which gave the study strong power to establish associations between the outcomes and covariates.

\section{Conclusion}

This study demonstrates the need to improve access to ITNs and the wider installation of house modification tools for vector control, especially among larger households. Specifically, the study suggests that large family households, households headed by young people, with low formal education, and the poorest households should be specifically targeted in keep-up and universal coverage campaigns, accompanied by $\mathrm{BCC}$ strategies for effective maximization of control tools. It is evident in the study that the wider installation of window screens could largely be improved by decreasing the associated costs through government subsidies. Therefore, it is recommended that strategies be put in place to improve access to window screens widely through low-cost screens and insecticidal screens to maximize their use in combination with ITNs to further control malaria as well as other vector-borne diseases.

\section{Abbreviations}

ANC: Antenatal Care; BCC: Behaviour Change Communication; DHS: Demographic Health Survey (Tanzania); GIS: Geographical Information System; IHI: Ifakara Health Institute; ITNs: Insecticide Treated Nets; NMCP: National Malaria Control Programme; NMSP: National Malaria Strategic Plan; PCA: Principal Component Analysis; SES: Socioeconomic Status; UCC: Universal Coverage Campaign; WHO: World Health Organization. 


\section{Acknowledgements}

We acknowledge the efforts of the Bagamoyo and Ifakara research teams (technicians) of the Ifakara Health Institute (IHI) and participants for taking their time to collect and provide data, respectively. Dr. Adam Saddler provided advice on study design, PD Dr. Christian Schindler's contribution to statistical analysis was helpful, as well as Raphael S. von Büren who provided guidance on map making on ArcGIS. Dr. Albert Kilian and Dr. Hannah Koenker provided guidance on the calculation of population access to ITNs.

\section{Authors' contributions}

OGO conducted study analysis and paper writing. AR contributed to the statistical analysis and major revision to the manuscript. YPM also contributed to the major revision of the manuscript and map making. OJ contributed to the manuscript's revision. SM contributed to data management and paper writing. DFM assisted substantially with data management and involved in manuscript writing. SJM conceived and designed the study, also contributed to analysis and paper writing. All authors read and approved the final manuscript.

\section{Funding}

The study was funded by the University of NOTRE DAME (UND Fund \#261655).

\section{Availability of data and materials}

Not applicable.

\section{Ethics approval and consent to participate}

Ethical clearance to conduct the survey was obtained from the Medical Research Coordinating Committee of the National Institute of Medical Research NIMR/HQ/R.8a/Nol. IX/1899 and the Institutional Review Board of the Ifakara Health Institute IHI/IRB/EXT/18-2015 and IHI/IRB/EXT/15-2017 and NIMR/HQ/R8.a/Nol IX/2270.

\section{Consent for publication}

Permission to publish was granted by Prof. Neil Lobo and Prof. Nicole Achee.

\section{Competing interests}

The authors declare no competing interests.

\section{Author details}

${ }^{1}$ Ifakara Health Institute, Bagamoyo, Tanzania. ${ }^{2}$ Swiss Tropical and Public Health Institute, Basel, Switzerland. ${ }^{3}$ University of Basel, Basel, Switzerland.

Received: 11 November 2019 Accepted: 18 June 2020

Published online: 23 June 2020

\section{References}

1. Bhatt S, Weiss DJ, Cameron E, Bisanzio D, Mappin B, Dalrymple U, et al. The effect of malaria control on Plasmodium falciparum in Africa between 2000 and 2015. Nature. 2015;526:207-11.

2. Levitz L, Janko M, Mwandagalirwa K, Thwai KL, Likwela JL, Tshefu AK, et al. Effect of individual and community-level bed net usage on malaria prevalence among under-fives in the Democratic Republic of Congo. Malar J. 2018;17:39.

3. WHO. Guidelines for malaria vector control. Geneva: World Health Organization; 2019.

4. Renggli S, Mandike R, Kramer K, Patrick F, Brown NJ, McElroy PD, et al. Design, implementation and evaluation of a national campaign to deliver 18 million free long-lasting insecticidal nets to uncovered sleeping spaces in Tanzania. Malar J. 2013;12:85.

5. Kulkarni MA, Vanden Eng J, Desrochers RE, Hoppe Cotte A, Goodson $J$, Johnston A, et al. Contribution of integrated campaign distribution of long-lasting insecticidal nets to coverage of target groups and total populations in malaria-endemic areas in Madagascar. Am J Trop Med Hyg. 2010;82:420-5.

6. Grabowsky M, Nobiya T, Elanikio J. Sustained high coverage of insecticide-treated bednets through combined catch-up and keep-up strategies. Trop Med Int Health. 2007;12:815-22.
7. Guyatt HL, Gotink MH, Ochola SA, Snow RW. Free bednets to pregnant women through antenatal clinics in Kenya: a cheap, simple and equitable approach to delivery. Trop Med Int Health. 2002;7:409-20.

8. Koenker H, Olapeju B, Toso M, Ricotta E. Insecticide-Treated Nets (ITN) Access and Use Report. Breakthrough ACTION and PMI VectorWorks projects, Johns Hopkins Center for Communication Programs. Published August 2019. Updated April 2020. http://itnuse.org/.

9. Okumu F. The paradigm of eave tubes: scaling up house improvement and optimizing insecticide delivery against disease-transmitting mosquitoes. Malar J. 2017;16:207.

10. Tusting LS, Ippolito MM, Willey BA, Kleinschmidt I, Dorsey G, Gosling RD, et al. The evidence for improving housing to reduce malaria: a systematic review and meta-analysis. Malar J. 2015;14:209.

11. Vanlerberghe V, Villegas E, Oviedo M, Baly A, Lenhart A, McCall PJ, et al. Evaluation of the effectiveness of insecticide treated materials for household level denque vector control. PLoS Negl Trop Dis. 2011;5:e994.

12. Ogoma SB, Lweitoijera DW, Ngonyani H, Furer B, Russell TL, Mukabana $W R$, et al. Screening mosquito house entry points as a potential method for integrated control of endophagic filariasis, arbovirus and malaria vectors. PLoS Negl Trop Dis. 2010:4:e773.

13. Ogoma SB, Kannady K, Sikulu M, Chaki PP, Govella NJ, Mukabana WR, et al. Window screening, ceilings and closed eaves as sustainable ways to control malaria in Dar es Salaam, Tanzania. Malar J. 2009;8:221.

14. Seidlein LV, Ikonomidis K, Mshamu S, Nkya TE, Mukaka M, Pell C, et al. Affordable house designs to improve health in rural Africa: a field study from northeastern Tanzania. Lancet Planet Health. 2017;1:188-99.

15. Lindsay SW, Wilson A, Golding N, Scott TW, Takken W. Improving the built environment in urban areas to control Aedes aegypti-borne diseases. Bull World Health Organ. 2017;95:607-8.

16. Weiss DJ, Nelson A, Gibson HS, Temperley W, Peedell S, Lieber A, et al. A global map of travel time to cities to assess inequalities in accessibility in 2015. Nature. 2018;553:333-6.

17. Juma OA, Enumah ZO, Wheatley H, Rafiq MY, Shekalaghe S, Ali A, et al. Prevalence and assessment of malnutrition among children attending the Reproductive and Child Health clinic at Bagamoyo District Hospital, Tanzania. BMC Public Health. 2016;16:1094.

18. Bardosh K, Sambo M, Sikana L, Hampson K, Welburn SC. Eliminating rabies in Tanzania? Local understandings and responses to mass dog vaccination in Kilombero and Ulanga districts. PLoS Negl Trop Dis. 2014;8:e2935.

19. The United Republic of Tanzania. 2012 Population and housing census: population distribution by administrative areas. Dar es Salaam: National Bureau of Statistics Ministry of Finance; 2013.

20. National Bureau of Statistics, Tanzania. Social economics of Tanzania, 2016 - Tanzania Data Portal, Knoema.

21. Alba S, Nathan R, Schulze A, Mshinda H, Lengeler C. Child mortality patterns in rural Tanzania: an observational study on the impact of malaria control interventions. Int J Epidemiol. 2014;43:204-15.

22. Kweka EJ, Kimaro EE., Kimaro EG, Nagagi YP, Malele II. Major disease vectors in Tanzania: distribution, control and challenges. In: Biological Control of Pest and Vector Insects. Shield V, Ed. IntechOpen, Chapt. 12. 2017.

23. Spatial Repellent Products for the Control of Vector Borne Diseases Malaria - Tanzania. ClinicalTrials.gov NCT02294214.

24. WHO Prequalified Vector Control Products. PQT-VC Reference: 001-001. 25/10/2017.

25. Koenker H, Arnold F, Ba F, Cisse M, Diouf L, Eckert E, et al. Assessing whether universal coverage with insecticide-treated nets has been achieved: is the right indicator being used ? Malar J. 2018;17:355

26. Theiss-Nyland K, Lynch M, Lines J. Assessing the availability of LLINs for continuous distribution through routine antenatal care and the Expanded Programme on Immunizations in sub-Saharan Africa. Malar J. 2016;15:255.

27. Lauritsen JM, Bruus M. EpiData (25th version). A comprehensive tool for validated entry and documentation of data. The EpiData Association, Odense, Denmark, 2003-2005.

28. StataCorp. Stata Statistical Software: Release 14. College Station: StataCorp LP; 2015.

29. Vyas S, Kumaranayake L. Constructing socio-economic status indices: how to use principal components analysis. Health Policy Plan. 2006:21:459-68. 
30. MEASURE Evaluation. Household survey indicators for malaria control. MEASURE DHS. President's Malaria Initiative. Roll Back Malaria Partnership. UNICEF. World Health Organization. 2013.

31. Matovu F, Goodman C, Wiseman V, Mwengee W. How equitable is bed net ownership and utilisation in Tanzania? A practical application of the principles of horizontal and vertical equity. Malar J. 2009;8:109.

32. Kirby MJ, Green C, Milligan PM, Sismanidis C, Jasseh M, Conway DJ, et al. Risk factors for house-entry by malaria vectors in a rural town and satellite villages in The Gambia. Malar J. 2008;7:2.

33. Noor AM, Omumbo JA, Amin AA, Zurovac D, Snow RW. Wealth, mother's education and physical access as determinants of retail sector net use in rural Kenya. Malar J. 2006;5:5.

34. Buchwald AG, Walldorf JA, Cohee LM, Coalson JE, Chimbiya N, Bauleni A, et al. Bed net use among school-aged children after a universal bed net campaign in Malawi. Malar J. 2016;15:127.

35. Schantz-Dunn J, Nour NM. Malaria and pregnancy: a global health perspective. Rev Obstet Gynecol. 2009;2:186-92.

36. Ender PB. The COLLIN program can be downloaded by using the FINDIT COLLIN command within Stata and selecting the appropriate hyperlink. Stata Journal.

37. President's Malaria Initiative Tanzania. Malaria Operational Plan FY 2019.

38. Tan KR, Coleman J, Smith B, Hamainza B, Katebe-Sakala C, Kean C, et al. A longitudinal study of the durability of long-lasting insecticidal nets in Zambia. Malar J. 2016;15:106.

39. Solomon T, Loha E, Deressa W, Balkew M, Gari T, Overgaard HJ, et al. Bed nets used to protect against malaria do not last long in a semi-arid area of Ethiopia: a cohort study. Malar J. 2018;17:239.

40. Msellemu D, Shemdoe A, Makungu C, Mlacha Y, Kannady K, Dongus S, et al. The underlying reasons for very high levels of bed net use, and higher malaria infection prevalence among bed net users than nonusers in the Tanzanian city of Dar es Salaam: a qualitative study. Malar J. 2017;16:423.

41. Kilian A, Koenker H, Obi E, Selby RA, Fotheringham M, Lynch M. Field durability of the same type of long-lasting insecticidal net varies between regions in Nigeria due to differences in household behaviour and living conditions. Malar J. 2015;14:123.

42. Kaindoa EW, Mkandawile G, Ligamba G, Kelly-Hope LA, Okumu FO. Correlations between household occupancy and malaria vector biting risk in rural Tanzanian villages: implications for high-resolution spatial targeting of control interventions. Malar J. 2016;15:199.

43. Stuck L, Lutambi A, Chacky F, Schaettle P, Kramer K, Mandike R, et al. Can school-based distribution be used to maintain coverage of long-lasting insecticide treated bed nets: evidence from a large scale programme in southern Tanzania ? Health Policy Plan. 2017;32:980-9.
44. Walldorf JA, Cohee LM, Coalson JE, Bauleni A, Nkanaunena K, KapitoTembo A, et al. School-age children are a reservoir of malaria infection in Malawi. PLoS ONE. 2015;10:e0134061.

45. Baume CA, Franca-Koh AC. Predictors of mosquito net use in Ghana. Malar J. 2011;10:265.

46. Massue DJ, Lorenz LM, Moore JD, Ntabaliba WS, Ackerman S, Mboma ZM, et al. Comparing the new Ifakara Ambient Chamber Test with WHO cone and tunnel tests for bioefficacy and non-inferiority testing of insecticidetreated nets. Malar J. 2019;18:153.

47. Atieli H, Menya D, Githeko A, Scott T. House design modifications reduce indoor resting malaria vector densities in rice irrigation scheme area in western Kenya. Malar J. 2009;8:108.

48. Kaindoa EW, Finda M, Kiplagat J, Mkandawile G, Nyoni A, Coetzee M, et al. Housing gaps, mosquitoes and public viewpoints: a mixed methods assessment of relationships between house characteristics, malaria vector biting risk and community perspectives in rural Tanzania. Malar J. 2018;17:298.

49. Lwetoijera DW, Kiware SS, Mageni ZD, Dongus S, Harris C, Devine GJ, et al. A need for better housing to further reduce indoor malaria transmission in areas with high bed net coverage. Parasit Vectors. 2013;6:57.

50. Simkovich SM, Goodman D, Roa C, Crocker ME, Gianella GE, Kirenga BJ, et al. The health and social implications of household air pollution and respiratory diseases. NPJ Prim Care Respir Med. 2019;29:12.

51. Polat F. Inclusion in education: a step towards social justice. Int J Educ Dev. 2011;31:50-8.

52. Kirby MJ, Ameh D, Green C, Jawara M, Milligan PJ, Bottomley C, et al. Efficacy of two different house screening interventions against exposure to malaria and anaemia in children in The Gambia: a randomized controlled trial. Lancet. 2009;374:998-1009.

53. Read AF, Lynch PA, Thomas MB. How to make evolution-proof insecticides for malaria control. PLoS Biol. 2009;7:e1000058.

54. Lindsay SW, Emerson PM, Charlwood JD. Reducing malaria by mosquitoproofing houses. Trends Parasitol. 2002;18:510-4.

55. Roxas B, Lindsay V. Social desirability bias in survey research on sustainable development in small firms: an exploratory analysis of survey mode effect. Bus Strategy Environ. 2012;21:223-35.

\section{Publisher's Note}

Springer Nature remains neutral with regard to jurisdictional claims in published maps and institutional affiliations.
Ready to submit your research? Choose BMC and benefit from:

- fast, convenient online submission

- thorough peer review by experienced researchers in your field

- rapid publication on acceptance

- support for research data, including large and complex data types

- gold Open Access which fosters wider collaboration and increased citations

- maximum visibility for your research: over $100 \mathrm{M}$ website views per year

At BMC, research is always in progress.

Learn more biomedcentral.com/submissions 